\title{
POSSIBILIDADES DE RE-ELABORAÇÃO DOS GÊNEROS DISCURSIVOS NO \\ PROCESSO DE APRENDIZAGEM DA LEITURA E DA ESCRITA NO ENSINO \\ FUNDAMENTAL, A PARTIR DO ENSINO DA LEITURA DIALÉTICA NA \\ EDUCAÇÃO INFANTIL
}

\section{POSSIBLE RE-DEVELOPMENT OF DISCURSIVE GENRES IN LEARNING PROCESS OF READING AND WRITING IN THE ELEMENTARY SCHOOL, FROM TEACHING DIALECTICAL READING IN THE EARLY CHILDHOOD EDUCATION}

\section{Rosangela Valachinski Gandin ${ }^{1}$}

\section{RESUMO}

O pensamento humano desenvolve-se num movimento dialético que tem o significado apreendido e internalizado como base para a compreensão de um novo conhecimento. Essa ocorre por meio da análise e da integração, resultando numa síntese. A leitura dialética ou interativa reúne elementos da leitura (tradicional) e da leitura ativa e promove uma interação entre os conhecimentos prévios e o enunciado do gênero discursivo, criando possibilidades de internalização de novos significados durante o processo de leitura tornando o leitor falante no processo comunicativo, porque externaliza o seu pensamento de acordo com os elementos do gênero. $\mathrm{O}$ ensino dos gêneros desde a educação infantil cria possibilidades do leitor no ensino fundamental (séries iniciais) reelaborar os enunciados internalizados oralmente em enunciados escritos.

Palavras- chave: Leitura dialética ou interativa; Ensino e aprendizagem de gênero discursivo.

\begin{abstract}
The human thought is developed in a dialectical movement which has the meaning seized and internalized as basis to the comprehension of a new knowledge. This happens through an analysis and integration, resulting in a synthesis. The dialectical or interactive reading gathers reading elements (traditional) and active reading and promotes an interaction between the previous knowledge and the enunciation of the discursive genre, creating possibilities of internalization of new meanings during the reading process turning the reader into speaker in the communication process, because it externalizes one's thought according to the genre elements. The genre teaching since kindergarten creates possibilities to the reader in the elementary education (early grades) re-establish the internalized enunciates orally into written ones.
\end{abstract}

Keywords: Dialectical or interactive reading; Teaching and learning of discursive genre.

Licenciada em Pedagogia, Mestranda em Educação pela UFPR, Pedagoga da UFPR E-mail: gandin_valachinski@yahoo.com.br

Divers@ Revista Eletrônica Interdisciplinar/Matinhos/Vol.5, n.1/p.1-92|/jan./jun.2012 
Introdução

Este artigo pretende refletir, a partir do estudo de alguns textos do Círculo de Bakhtin, da teoria do desenvolvimento do pensamento infantil na perspectiva de Vygotsky, da estratégia de leitura proposta pela autora Isabel Solé e da sequência didática de ensino de gêneros orais e escrito proposta por Dolz et al, sobre a importância de ler diversos gêneros discursivos na educação infantil e tem como objetivo fornecer elementos teóricos para o trabalho de pesquisa que pretende investigar, a partir da realidade cognitiva de crianças matriculadas do $1^{\circ}$ ao $5^{\circ}$ ano fundamental e das situações de aprendizagem propostas pelos professores, o estágio da construção da aprendizagem da leitura, da interpretação e da escrita nos gêneros textuais narrativos.

\section{Concepção de leitura e o ensino da leitura dialética desde a Educação Infantil}

Por muitas décadas no Brasil, o processo de aquisição da leitura, da escrita e da compreensão dos textos foi notoriamente gerenciado por situação de aprendizagem que priorizavam a leitura da menor unidade linguística até atingir o nível da frase, onde o leitor em formação, após a união dos significados das unidades linguísticas, obteria o significado do texto lido ou escutado, ou seja, uma leitura passiva característica da concepção da leitura tradicional, conforme ilustra o gráfico a seguir.

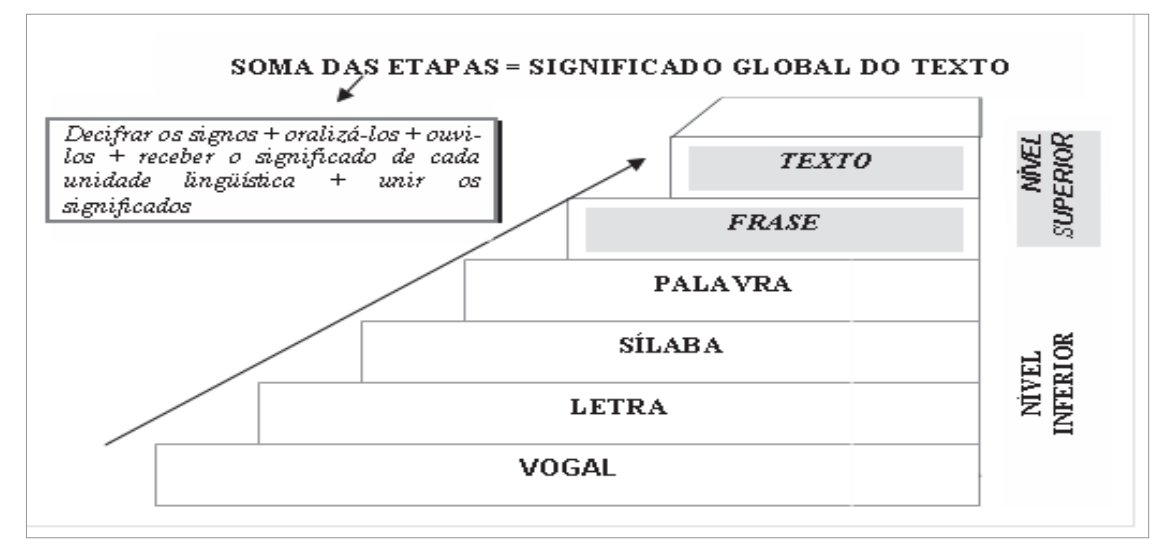

Gráfico 1: Leitura Tradicional - Processo Ascendente.

Fonte: A autora. Construído a partir do texto O que é ler? In: Ensinar a ler, ensinar a compreender. Teresa Colomer e Anna Camps. Porto Alegre: Artmed, 2002.

Divers@ Revista Eletrônica Interdisciplinar/Matinhos/Vol.5, n.1/p.1-92//jan./jun.2012 
$\mathrm{Na}$ segunda metade do século XX, a concepção da leitura ativa que fornece o significado do texto a partir da significação das palavras e constante raciocínio do leitor no enunciado explícito e o que está nas entre linhas, passou a circular nas propostas de ensino da leitura, da escrita e da compreensão textual. O gráfico a seguir, ilustra o processo descendente preconizada pela leitura ativa.

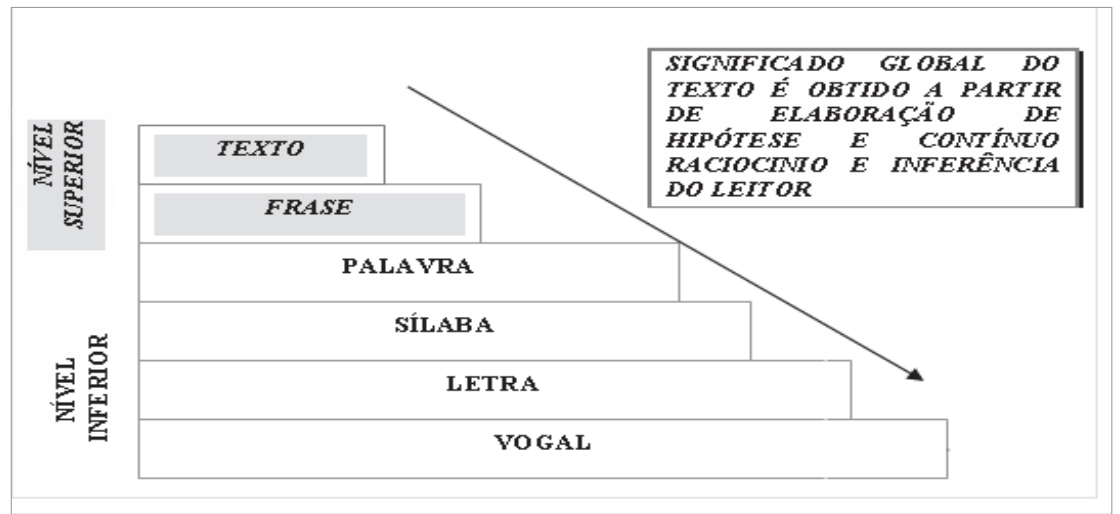

Gráfico 2: Leitura Ativa - Processo Descendente.

Fonte: A autora. Construído a partir do texto O que é ler? In: Ensinar a ler, ensinar a compreender. Teresa Colomer e Anna Camps. Porto Alegre: Artmed, 2002.

Nesta concepção, o ato de ler parte do todo para parte, ou seja, o leitor em formação lê ou escuta primeiramente o texto, para posteriormente decodificar a língua materna até a sua menor unidade linguística, seguida de codificação do enunciado e constante elaboração da hipótese para chegar ao nível da compreensão do enunciado na sua totalidade.

O processo de compreensão responsiva, observando as peculiaridades de cada gênero textual, em propostas de aprendizagem a partir destas concepções, não é destacado como importante para o desenvolvimento do pensamento e da compreensão leitora interativa, tendo em vista que as preocupações centralizam-se em operações mentais unicamente no objeto, ora na aprendizagem da unidade linguística conforme postula a leitura tradicional, ora no enunciado como objeto de estudo linguístico e de constatação de hipóteses a partir do enunciado do autor como propõem a leitura ativa, ou seja, enfatizam o ensino da língua com base no objetivismo abstrato conforme destaca Bakhtin (2010, p. 93 - 113) quando o estudo da língua concentrar-se fora do seu contexto social, é um estudo de uma língua morta porque apresenta significados acabados e prontos, isto é, uma língua normatizada vazia de ideologia, pois:

Na prática viva da língua, a consciência linguística do locutor e do receptor nada tem a ver com um sistema abstrato de formas normativas, mas apenas com a linguagem

Divers@ Revista Eletrônica Interdisciplinar/Matinhos/Vol.5, n.1/p.1-92|/jan./jun.2012 
no sentido de conjunto dos contextos possíveis de uso de cada forma particular. (BAKHTIN, 2010, p. 98)

Se a língua, ou melhor, a utilização concreta de um enunciado com todos os seus elementos (o conteúdo temático, o estilo, a composição) é quem cria possibilidades de compreensão, pode-se deduzir que esse enunciado é capaz de criar uma zona de desenvolvimento proximal - ZDP, pois para Vygotsky $(1984,2010)$ a aprendizagem é anterior ao desenvolvimento, porque a aprendizagem gera o desenvolvimento a partir da ZDP, ou seja, é a partir das ações desenvolvidas pelo sujeito e por meio da interação social que ocorre a apropriação dos conhecimentos produzidos pela humanidade, pois a ZDP:

É a distância entre o nível de desenvolvimento real, que se costuma determinar através da solução independente de problemas, e o nível de desenvolvimento potencial, determinado através da solução de problemas sobre a orientação de um adulto ou em colaboração com companheiros mais capazes. (VIGOTSKI, 1984, p. 112).

Se a zona de desenvolvimento proximal é o espaço para ação educativa por excelência, é também o espaço para a fala do outro, a voz do discurso do outro, pois o ser humano tornase ele mesmo a partir do olhar do outro, porque para Vigotsky (1989, apud, Pino, 2000, p. 54) 2 “o desenvolvimento cultural passa por três estágios: desenvolvimento em si, para os outros, e para si mesmo".

Os estágios apresentados acima é uma analogia à dialética de Hegel, no entanto, Vygotsky, inclui algo novo, ou seja, o para os outros, que em outras palavras, significa o olhar que o mediador cultural já elaborou a respeito da cultura e a partir das interações, transmite as significações para o desenvolvimento para si, no entanto, do outro. Em síntese, nos tornamos sujeitos sociais pela leitura e internalização do discurso do outro, num processo interno, que resulta no desenvolvimento de si mesmo e que para Bakhtin resulta na construção do próprio enunciado do falante ou do escritor, conforme suas palavras:

Por isso pode-se dizer que qualquer palavra existe para o falante em três aspectos: como palavra da língua neutra e não pertencente a ninguém; como palavra alheia dos outros, cheia de ecos de outros enunciados; e, por último, como a minha palavra, porque, uma vez que eu opero com ela em uma situação determinada, com uma intenção discursiva determinada, ela já está compenetrada da minha expressão... A experiência discursiva individual de qualquer pessoa se forma e se desenvolve em uma interação constante e contínua com os enunciados individuais dos outros. Em certo sentido, essa experiência pode ser caracterizada como processo de assimilação - mais ou menos criador - das palavras do outro (e não das palavras da língua). (BAKHTIN, 2010, p. 294).

2 VIGOTSKI, L. S. Concrete humam psychology. Soviet Psychology, XXVII (2), pp. 53-77.

Divers@Revista Eletrônica Interdisciplinar/Matinhos/Vol.5, n.1/p.1-92|/jan./jun.2012 
A linguagem e o enunciado do outro que, por sua vez, podem ser apresentados tanto na linguagem oral ou na linguagem escrita, tem papel fundamental nesse processo de vir a ser, uma vez que é por meio dela que a comunicação ocorre, assim como a palavra possui uma função importantíssima durante a leitura e a construção das interpretações dos enunciados dos outros, pois segundo Bakhtin (2010, p. 97) “a assimilação ideal de uma língua dá-se quando o sinal é completamente absorvido pelo signo e o reconhecimento pela compreensão".

Por meio dessas palavras é possível deduzir hipoteticamente a importância da voz do discurso do outro e do conhecimento prévio do leitor na comunicação discursiva, pois para a leitura dialética ou interativa, o enunciado durante o processo de compreensão cria possibilidades de internalização do significado do discurso alheio, culminando num ato interativo na compreensão responsiva.

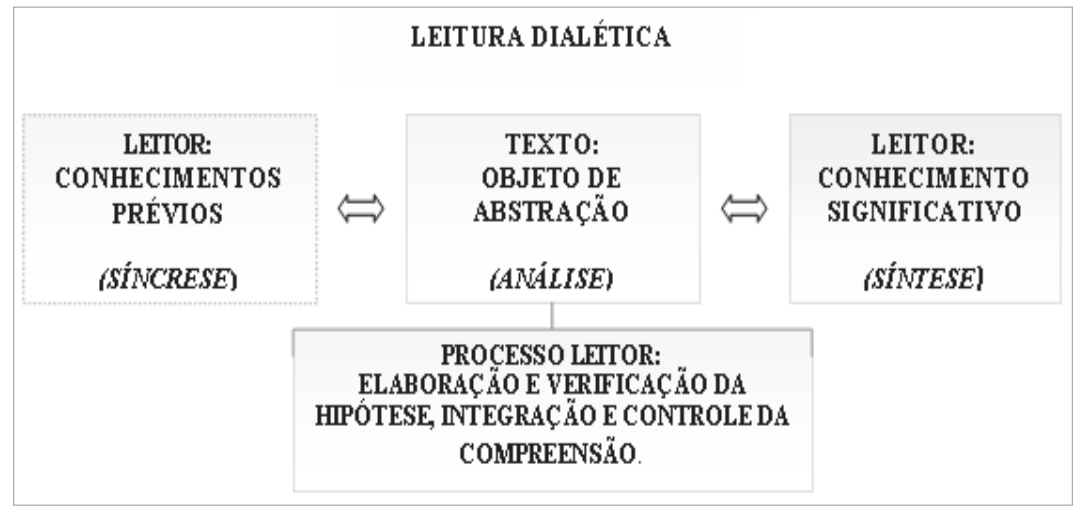

Gráfico 3: Esquema da Leitura Dialética ou Interativa

Fonte: Construído a partir da leitura do livro Ensinar a ler, ensinar a compreender de Teresa Colomer e Anna Camps (2002) e de Uma didática para Pedagoga Histórico-crítica de João Luiz Gasparin (2003).

O esquema da leitura dialética ilustra o processo da compreensão responsiva ${ }^{3}$ para qualquer gênero textual, independente se este encontrar-se na linguagem oral ou na escrita.

Se estratégias de leitura que objetivam a compreensão do leitor, tais como às apresentadas pela autora Isabel Solé (1998) que em síntese trata-se de incentivar a elaboração de hipóteses antes de ler o texto, continuar incentivando a elaboração de hipóteses durante o processo de leitura, criando atitude responsiva que possibilite a criança constatar as hipóteses elaboradas, seguida de releitura após a leitura com as crianças para verificação do que foi

3 Para Bakhtin (2010, p. 270) Compreensão Responsiva refere-se à compreensão da fala viva e de atitude responsiva, ou seja, a capacidade do ouvinte (e do leitor) dialogar com o falante (e com o escritor) e neste espaço do discurso responder ativamente concordando ou não com a mensagem do falante inicial, tornando-se, também falante no discurso.

Divers@ Revista Eletrônica Interdisciplinar/Matinhos/Vol.5, n.1/p.1-92|/jan./jun.2012 
compreendido, forem incluídas nas situações de aprendizagem escolar, é possível trabalhar com leitura de diversos gêneros textuais a partir da educação infantil, pois:

Cada enunciado deve ser visto antes de tudo como uma resposta aos enunciados precedentes de um determinado campo (aqui concebemos a palavra "resposta" no sentido mais amplo): ela os rejeita, confirma, completa, baseia-se neles, subentendeos como conhecidos, de certo modo os leva em conta. Porque o enunciado ocupa uma posição definida em uma dada esfera da comunicação, em uma dada questão, em um dado assunto, etc. É impossível alguém definir sua posição sem correlacionála com outras posições. Por isso, cada enunciado é pleno de variadas atitudes responsivas a outros enunciados de dada esfera da comunicação discursiva. (BAKHTIN, 2010, p. 297, grifos do autor).

\title{
Porque estudar os enunciados dos gêneros desde a educação infantil?
}

Se o enunciado é uma resposta ao enunciado do outro e a aprendizagem contribui para o desenvolvimento da compreensão leitora, portanto, essa compreensão é possível de ser atingida e, quanto mais cedo a criança entrar em contato e vivenciar leituras que lhe permitem reelaborar o enunciado de um determinado gênero do discurso e internalizar as signifícações e formas de falar de acordo com a composição do gênero, mais cedo essa criança será introduzida no processo de leitura, compreensão e produção de textos de uso efetivo na comunicação, pois:

\begin{abstract}
Quanto melhor dominamos os gêneros tanto mas livremente os empregamos, tanto mais plena e nitidamente descobrimos neles a nossa individualidade (onde isso é possível e necessário), refletimos de modo mais flexível e sutil a situação singular da comunicação; em suma, realizamos de modo mais acabado o nosso livre projeto de discurso... Desse modo, ao falante não são dadas apenas as formas da língua nacional (a composição vocabular e a estrutura gramatical) obrigatórias para ele, mas também as formas de enunciado para ele obrigatórias, isto é, os gêneros do discurso: estes são tão indispensáveis para a compreensão mútua quanto as formas da língua. Os gêneros do discurso, comparados às formas da língua, são bem mais mutáveis, flexíveis e plásticos; entretanto, para o indivíduo falante eles têm significado normativo, não são criados por ele mas dados a ele. (BAKHTIN, 2010, p. 285).
\end{abstract}

Se os gêneros são dados à criança, isto vem ao encontro com o processo de desenvolvimento apresentado anteriormente, portanto, possível de ser ensinado mesmo antes da criança ser alfabetizada, apesar da linguagem oral ser a predominante na educação infantil e a descoberta da escrita como representação do que se fala estar por vir a ser, existem situações de aprendizagem que poderão ser propostas pelos mediadores culturais desde que criam ZDP's de acordo com o estágio de desenvolvimento do pensamento infantil descrito por Vygotsky (1993), isto é, atividades que transitem entre estágio do pensamento sincrético e o

Divers@Revista Eletrônica Interdisciplinar/Matinhos/ Vol.5,n.1/p.1-92//jan./jun.2012 
estágio do pensamento por complexos, pois é só final da adolescência que o falante é capaz de operar com os conceitos científicos plenamente, pois:

$\mathrm{O}$ adulto não pode transmitir à criança o seu modo de pensar. Ele apenas lhe apresenta o significado acabado de uma palavra, ao redor da qual a criança forma um complexo com todas as peculiaridades estruturais, funcionais e genéticas do pensamento por complexos, mesmo que o produto de seu pensamento seja de fato idêntico, em seu conteúdo, a uma generalização que poderia ter-se formado através do pensamento conceitual. (VYGOTSKY, 1993, p. 58).

É no processo interativo e no final da adolescência que o falante, o escritor e o leitor poderão utilizar livremente os gêneros discursivos apreendidos no ensino fundamental, por que:

O desenvolvimento dos processos que finalmente resultam na formação de conceitos começa na fase mais precoce da infância, mas as funções intelectuais que, numa combinação específica, forma a base psicológica do processo da formação de conceitos amadurece, se configura e se desenvolve na puberdade. (VYGOTSKY, 1993, p. $49-50)$.

\section{A construção dos enunciados de acordo com o gênero do discurso e com o estágio de desenvolvimento do pensamento}

Para Vygotsky (1993) é na idade escolar que a fala interior começa a ter sua maior expressão e deduz-se que isso coincide com o processo de decodificação e codificação da língua materna, portanto, momento de aprendizagem favorável para a criança ler e interpretar enunciados completos e iniciar o processo de registro de sua interpretação na linguagem escrita, pois para aquele autor (1993, p. 113) “a fala interior é para si mesmo; a fala exterior é para os outros".

Se, no ensino fundamental séries iniciais, a criança realiza a reelaboração do que internalizou na fala interior, onde acontece o processo e o controle da compreensão responsiva, e consequentemente representa na escrita ou na linguagem oral o enunciado na forma solicitada pelo tipo e gênero do discurso ${ }^{4}$, logo esse processo poderá tornar-se mais efetivo, sequencial e motivador se, essa criança tiver escutado, lido ou vivenciado diversos gêneros discursivos na educação infantil, pois ao realizar as ações, a criança estará acionando processos internos promovidos por ZDP's que contribuíram com o desenvolvimento da internalização do gênero em vivência, pois segundo Vygotsky:

4 Dolz e Schneuwly (2004, p. 51-52) apresentam cinco domínios sociais de comunicação como tipos de gêneros, a saber: narrativa, relato, argumentação, exposição e descrição de ações.

Divers@ Revista Eletrônica Interdisciplinar/Matinhos/Vol.5, n.1/p.1-92|/jan./jun.2012 
Uma criança não se comporta de forma puramente simbólica no brinquedo; ao invés disso, ela quer e realiza seus desejos, permitindo que as categorias básicas da realidade passem através de sua experiência. A criança, ao querer, realiza seus desejos. Ao pensar, ela age. As ações internas e externas são inseparáveis: a imaginação, a interpretação e a vontade são processos internos conduzidos pela ação externa. (VYGOSTKY, 1984, p. 132).

Portanto, ao dramatizar gêneros a criança estará vivendo os elementos que o compõem e internalizando-os, para mais tarde, ao longo do processo de aprendizagem no ensino fundamental séries iniciais, passar a criar narrativas a partir dos conhecimentos prévios internalizados naquele nível educacional, tornando possível a reelaboração do que anteriormente foi uma brincadeira educativa, transportando-a para produção de narrativas na linguagem escrita, pois:

Os enunciados dos outros podem ser recontados com um variado grau de reassimilação; podemos simplesmente nos basear neles como em um interlocutor bem conhecido, podemos pressupô-los em silêncio, a atitude responsiva pode refletir-se somente na expressão do próprio discurso - na seleção de recursos linguísticos e entonações, determinada não pelo objeto do próprio discurso mas pelo enunciado do outro sobre o mesmo objeto. (BAKHTIN, 2010, p. 297)

$\mathrm{O}$ estudo dos gêneros desde o $1^{\circ}$ ano escolar poderá contribuir com o processo de aquisição da escrita e seu uso efetivo no cotidiano, demonstrando à criança a relação estreita entre o enunciado, os elementos que o compõem com a realidade concreta, uma vez que:

O estudo da natureza dos enunciados e dos gêneros discursivos é, segundo nos parece, de importância fundamental para superar as concepções simplificadas da vida do discurso, do chamado "fluxo discursivo", da comunicação, etc., daquelas concepções que ainda dominam a nossa linguística. Além do mais, o estudo do enunciado como unidade real da comunicação discursiva permitirá compreender de modo mais correto também a natureza das unidades da língua (enquanto sistema) as palavras e orações. (BAKHTIN, 2010, p. 269).

Ao criar situação de aprendizagem de leitura e produção de gêneros discursivos estreitamente ligadas ao cotidiano da criança, é propor um ensino da leitura e da escrita vivos, pois as mesmas poderão tornar-se leitoras e falantes no discurso e experimentar o uso efetivo do gênero do discurso em estudo, respeitando evidentemente o nível de desenvolvimento do pensamento, que segundo Vygotsky, neste nível de ensino, encontra-se no estágio do pensamento por complexos, conforme citação a seguir:

Em um complexo, as ligações entre seus componentes são concretas e factuais, e não abstratas e lógicas... As ligações factuais subjacentes aos complexos são descobertas por meio da experiência direta. Portanto, um complexo é, antes de mais nada, um agrupamento concreto de objetos unidos por ligações factuais. (VYGOTSKY, 1993, p. 53).

Divers@Revista Eletrônica Interdisciplinar/Matinhos/Vol.5,n.1/p.1-92//jan./jun.2012 
Se a proposta de ensino de gênero for elaborada de acordo com a sequência didática proposta por Dolz et al (2004) que, por sua vez, inicia com a apresentação de uso efetivo do gênero, ou seja, explicar a necessidade de estudar e escrever por exemplo, seguida de uma primeira produção de textos, para mais tarde, serem trabalhados os elementos necessários para a criança desenvolver o texto de acordo com a composição do gênero até concluir a versão final do estilo de enunciado proposto, é contribuir com o processo de desenvolvimento da escrita, por que:

A evolução do rascunho para a cópia final reflete nosso processo mental. O planejamento tem um papel importante na escrita, mesmo quando não fazemos um verdadeiro rascunho. Em geral, dizemos a nós mesmos o que vamos escrever, o que já constitui um rascunho, embora apenas em pensamento. (...) esse rascunho mental é uma fala interior. (...) esta funciona como rascunho não apenas na escrita, mas também na fala oral. (VYGOTSKY, 1992, p. 124).

Para ilustrar o processo de desenvolvimento da escrita narrativa, abaixo segue uma tabela com sugestões de algumas atividades de leitura e escrita que poderão ser realizadas pelas crianças com a mediação do professor. Porém, alerta-se que o elenco de atividades não se esgota no quadro a seguir, caberá ao docente após a realização da avaliação diagnóstica listar e planejar o ensino dos saberes, ainda, necessário de serem internalizados pela criança.

\begin{tabular}{|c|c|c|c|}
\hline \multicolumn{4}{|c|}{ Exemplo da sequência didática para o ensino de textos narrativos } \\
\hline Etapa & Módulo & Objetivo & Atividade \\
\hline \multirow[t]{2}{*}{$1^{\mathrm{a}}$} & \multirow{2}{*}{$\begin{array}{l}\text { Conhecendo o } \\
\text { gênero } \\
\text { narrativo }\end{array}$} & $\begin{array}{l}\text { Elaborar projeto coletivo de } \\
\text { produção de texto narrativo, } \\
\text { refletindo sobre os conteúdos que } \\
\text { serão comunicados neste texto. }\end{array}$ & $\begin{array}{l}\text { Leitura de diversos tipos de textos narrativos, } \\
\text { tais como: conto, notícia, lenda, contos } \\
\text { canônicos, carta, etc. }\end{array}$ \\
\hline & & $\begin{array}{l}\text { Realizar avaliação diagnóstica } \\
\text { para verificar quais os } \\
\text { conhecimentos sobre a escrita } \\
\text { narrativa as crianças possuem. }\end{array}$ & $\begin{array}{l}\text { Escrever um texto narrativo a partir de um } \\
\text { tema ou situação problema. }\end{array}$ \\
\hline \multirow{5}{*}{$2^{\mathrm{a}}$} & \multirow[t]{2}{*}{$\begin{array}{l}\text { Compondo o } \\
\text { gênero } \\
\text { narrativo }\end{array}$} & $\begin{array}{l}\text { Identificar as partes que compõem } \\
\text { uma narrativa }\end{array}$ & $\begin{array}{l}\text { Ler partes de textos narrativos. } \\
\text { Trabalhar com quebra cabeça de partes } \\
\text { textuais. } \\
\text { Produzir final ou a situação problema } \\
\text { requerida pelo texto. }\end{array}$ \\
\hline & & $\begin{array}{l}\text { Produzir um texto a partir de um } \\
\text { tema ou de uma situação } \\
\text { problema. }\end{array}$ & Trabalhar produção de pequenos textos \\
\hline & \multirow{3}{*}{$\begin{array}{l}\text { Conhecimento } \\
\text { Linguístico } \\
\text { necessários à } \\
\text { Produção de }\end{array}$} & $\begin{array}{l}\text { Identificar os sinais de pontuação } \\
\text { utilizados no texto narrativo. }\end{array}$ & $\begin{array}{l}\text { Trabalhar os diferentes tipos de sinais de } \\
\text { pontuação exigidos pelo texto narrativo. }\end{array}$ \\
\hline & & $\begin{array}{l}\text { Conhecer os registros de sons e } \\
\text { emoções expressos em palavras. }\end{array}$ & $\begin{array}{l}\text { Registrar graficamente: o som de um beijo, } \\
\text { expressão de alegria e felicidade, tristeza, } \\
\text { espanto, horror, etc. }\end{array}$ \\
\hline & & em textos & Leitura de textos onde a elipse aparece. \\
\hline
\end{tabular}

Divers@Revista Eletrônica Interdisciplinar/Matinhos/ Vol.5,n.1/p.1-92//jan./jun.2012 


\begin{tabular}{|l|l|l|l|}
\hline \multirow{3}{*}{$\begin{array}{l}\text { textos } \\
\text { narrativos }\end{array}$} & narrativos & $\begin{array}{l}\text { Identificar elementos coesivos } \\
\text { anafóricos e catafóricos }\end{array}$ & $\begin{array}{l}\text { Leitura de textos onde ocorre a coesão } \\
\text { anafórica e catafórica. } \\
\text { Leitura de texto apresentado em uma das } \\
\text { variações do close. }\end{array}$ \\
\hline \multirow{3}{*}{$3^{\text {a }}$} & $\begin{array}{l}\text { Revisando } \\
\text { escrevendo } \\
\text { narrativas }\end{array}$ & $\begin{array}{l}\text { Listar com as crianças as } \\
\text { aprendizagens que ocorreram. }\end{array}$ & $\begin{array}{l}\text { Registrar em cartazes ou no caderno as } \\
\text { aprendizagens atingidas. }\end{array}$ \\
\cline { 2 - 5 } & $\begin{array}{l}\text { Revisar a produção textual inicial. } \\
\text { narrativa a versão final da }\end{array}$ & $\begin{array}{l}\text { Ler individualmente ou em dupla o texto } \\
\text { inicial }\end{array}$ \\
\hline $\begin{array}{l}\text { Escrever uma nova versão textual, corrigindo } \\
\text { as inadequações encontradas na revisão. }\end{array}$ \\
\hline
\end{tabular}

Tabela 1 - Exemplo da sequência didática para o ensino de textos narrativos.

Fonte: Elaborado a partir da leitura DOLZ, Joaquim et al (2004), KOCH (2004, 2006), Gladys Rocha (1999) e Leal et al (2001).

Como podem ser observadas, as atividades sugeridas estão diretamente ligada à produção textual e não, simplesmente, a um ensino voltado para a memorização de regras gramaticais ou na produção de frases sem sentido. No exemplo a produção narrativa está direcionada à situação comunicativa, que por sua vez, é comentado com a criança desde o início das atividades e os saberes, ainda, não compreendidos pelo pequeno escritor é trabalhado de acordo com as reais necessidades de aprendizagem e com a estrutura do gênero narrativo.

\section{Conclusão}

O processo de desenvolvimento da compreensão está repleto de enunciados dos outros que, por sua vez, encontra-se com os enunciados internalizados do leitor e do escritor em formação, provocando abstração, seguida de análise e elaboração de uma síntese, externalizando-a por meio de enunciados, seja na linguagem oral ou na escrita.

Portanto, se o ensino dos gêneros discursivos for contemplado nas propostas da educação infantil, se estiver de acordo com o nível de desenvolvimento do pensamento infantil e se for organizado com práticas pedagógicas que permitam a criança vivenciar esses enunciados, tais como: leitura com mediação, dramatização de textos da literatura infantil, jogos voltados para aprendizagem da leitura e da escrita, etc., poderá contribuir na aquisição da leitura, da escrita no ensino fundamental séries iniciais a partir de enunciados internalizados nas etapas anteriores, porque é muito mais fácil, gratificante e prazeroso para a criança aprender a escrever textos que já conhece na linguagem oral e não há problema algum retomar conteúdos trabalhados em níveis escolares anteriores por duas razões: primeiro porque a retomada do conteúdo servirá para consolidar a aprendizagem que antes estava na

Divers@Revista Eletrônica Interdisciplinar/Matinhos/Vol.5,n.1/p.1-92//jan./jun.2012 
linguagem oral, que por sua vez, estará sendo transformada em linguagem escrita considerando toda a especificidade dessa, e segundo, considerado que a aprendizagem acontece a partir da análise e reflexão do conhecimento novo com o conhecimento internalizado, que após integração, resultará em uma nova síntese, que servirá de base para consolidação de conhecimentos futuros na aprendizagem da leitura e da escrita no ensino fundamental séries finais.

\section{Referências}

BAKTHIN, M. M. Estudo das ideologias e filosofia da linguagem. In: Marxismo e filosofia da linguagem: problemas fundamentais do método sociológico da linguagem. Prefácio de Roman Jakobson, apresentação de Marina Yaguello; tradução de Michel Lahud et al. 14. Ed. São Paulo: Hucitec, 2010.

A relação entre a infra-estrutura e as superestruturas. In: Marxismo e filosofia da linguagem: problemas fundamentais do método sociológico da linguagem. Prefácio de Roman Jakobson, apresentação de Marina Yaguello; tradução de Michel Lahud et al. 14. Ed. São Paulo: Hucitec, 2010.

Língua, fala e enunciação. In: Marxismo e filosofia da linguagem: problemas fundamentais do método sociológico da linguagem. Prefácio de Roman Jakobson, apresentação de Marina Yaguello; tradução de Michel Lahud et al. 14. Ed. São Paulo: Hucitec, 2010.

Tema e significação na língua. In: Marxismo e filosofia da linguagem: problemas fundamentais do método sociológico da linguagem. Prefácio de Roman Jakobson, apresentação de Marina Yaguello; tradução de Michel Lahud et al. 14. Ed. São Paulo: Hucitec, 2010.

Os gêneros do discurso. In: Estética da criação verbal. 4. Ed. São Paulo: Martins Fontes, 2003.

COLOMER, Teresa e CAMPS, Anna. Ensinar a ler, ensinar a compreender. Tradução de Fátima Murad. Porto Alegre: Artmed, 2002.

DOLZ, Joaquim; NOVERRAZ, Michele e SCHNEUWBY, Bernard. Sequências didáticas para o oral e a escrita: apresentação de um procedimento. In: Gêneros orais e escritos na escola. Tradução de Roxane Rojo e Glais Sales Cordeiro. Campinas, SP: Mercado das Letras, 2004.

Divers@Revista Eletrônica Interdisciplinar/Matinhos/Vol.5, n.1/p.1-92//jan./jun.2012 
DOLZ, Joaquim e SCHNEUWBY, Bernard. Gêneros e progressão em expressão oral e escrita - elementos para reflexões sobre uma experiência suíça (francófona). In: Gêneros orais e escritos na escola. Tradução de Roxane Rojo e Glais Sales Cordeiro. Campinas, SP: Mercado das Letras, 2004.

FOUCAMBERT, Jean. Modos de ser leitor: Aprendizagem e ensino da leitura no ensino fundamental. Tradução Lucia P. Cherem e Suzete P. Bornatto. Curitiba: UFPR, 2008.

$\mathrm{KOCH}$, Ingedore G. V. Introdução à linguística textual: trajetórias e grandes temas. São Paulo: Martins Fontes, 2004.

A coesão textual. 20 Ed. São Paulo: Contexto, 2005.

Concepções de língua, sujeito, texto e sentido. In: Desvendo os segredos do texto. 5. Ed. São Paulo: Cortez, 2006. p. 13 - 20.

TRAVAGLIA, Luiz C. A coerência textual. 17. Ed. São Paulo: Contexto, 2006.

LEAL, Telma F. e LUZ, Patrícia Santos. Produção de textos narrativos em pares: Reflexões sobre os processos de interação. In: Educação e Pesquisa (USP), São Paulo, V. 27, p. 27-46, 2001.

LURIA, A. R. O desenvolvimento da escrita na criança. In: Vygotsky, L. S. et al. Linguagem, desenvolvimento e aprendizagem. 7. Ed. São Paulo: Ícone, 2001.

A psicologia experimental e o desenvolvimento infantil. In: Vygotsky, L. S. et al. Linguagem, desenvolvimento e aprendizagem. 7. Ed. São Paulo: Ícone, 2001.

PINO, Angel. A psicologia concreta de Vigotski: implicações para a educação. In: Psicologia \& educação: Revendo contribuições. Abigail Alvarenga Mahoney et al. Vera Maria Nigro de Souza Placco (Org.). São Paulo: Educ, 2000.

ROCHA, Gladys. A apropriação das habilidades textuais pela criança. Campinas, SP: Papirus, 1999.

SCHNEUWLY, Bernad; DOLZ, Joaquim. Gêneros orais e escritos na escola. Tradução de Roxane Rojo e Glais Sales Cordeiro. Campinas, SP: Mercado das Letras, 2004.

SOLÉ, Isabel. Estratégia de leitura. Tradução Fátima Murad. 6. Ed. Porto Alegre: Artmed, 1998.

VIGOTSKI, L. S. A formação social da mente. São Paulo: Martins Fontes, 1984.

Divers@ Revista Eletrônica Interdisciplinar/Matinhos/Vol.5, n.1/p.1-92//jan./jun.2012 
O problema do ensino e do desenvolvimento mental na idade escolar. In: Psicologia pedagógica. Tradução do russo e introdução de Paulo Bezerra. 3. Ed. São Paulo: WMF Martins Fontes, 2010. p. 465-487.

Desenvolvimento dos conceitos cotidianos e científicos na idade escolar. In: Psicologia pedagógica. Tradução do russo e introdução de Paulo Bezerra. 3. Ed. São Paulo: WMF Martins Fontes, 2010. p. 517-545.

VYGOTSKY, L.S. Pensamento e linguagem. Tradução Jéferson Luiz Camargo; revisão técnica José Cipolla Neto. São Paulo: Martins Fontes, 1993.

VYGOTSKY, L. S; LURIA, A. R. A criança e seu comportamento. In: Estudos sobre a história do comportamento: o macaco, o primitivo e a criança. Victor I. Golod (Coord e org.); tradução de Lólio Lourenço de Oliveira. Porto Alegre: Artes Médicas, 1996. p. 151238.

VYGOTSKY, L. S; Aprendizagem e desenvolvimento intelectual na idade escolar In: Vygotsky, L. S. et al. Linguagem, desenvolvimento e aprendizagem. São Paulo: Ícone, 2001. 